\title{
IMAGEM SOCIAL OU LUTA POLÍTICA E CULTURAL PELO CONTROLE DO MERCADO
}

Gilles Laferté

Apresentaremos aqui uma proposta geral de pesquisa, retomada em numerosos trabalhos contemporâneos que tratam da questão hoje rotineira da "construção das identidades", por intermédio do estudo da reviravolta do mercado de vinhos da Borgonha, na França, no período do entre guerras em proveito dos proprietários e em detrimento dos comerciantes - fato que conduziu à redefinição da imagem da região. ${ }^{1}$ Com efeito, se desde os anos 1980, a "construção de identidades" tem permitido desnaturalizar a rígida noção de identidade e retomar a análise dos fenômenos culturais em termos de uma dinâmica social preocupada com as posições sociais e as correlações de força, devemos constatar, no entanto, o atual enfraquecimento das capacidades heurísticas desta fórmula que, do nosso ponto de vista, comporta mais inconvenientes do que vantagens.

Assim sendo, em um primeiro momento, nos propomos a retomar mais detidamente a literatura que trata da noção de identidade nas ciências sociais francesas para melhor compreendermos, por um lado, os avanços por ela permitidos e, por outro, seu desgaste diante da multiplicidade de processos sociais que recobre. A fórmula da construção das identidades passa a funcionar, a partir de então, como um obstáculo epistemológico que privilegia um construtivismo discursivo, conferindo uma visão excessivamente plástica às evoluções sociais.

Ao adotar um vocabulário alternativo para analisar não mais a identidade, mas a imagem social da Borgonha e dos vinhos da região, atentando para não confundir a produção de um discurso sobre os grupos e os territórios - feita pelas elites sociais — com as socializações ou a apropriação destes mesmos discursos pelas categorias populares, privilegiamos o que poderíamos denominar, portanto, de um construtivismo institucional e estrutural. Trata-se aqui de mostrar a riqueza do conjunto de redes sociais e de evoluções institucionais indispensáveis num momento anterior que ao 
final conduzem - em uma combinação até então imprevisível - a uma prática social particular: a produção de um novo discurso regional, uma nova imagem da Borgonha via folclorização, possibilitada pela aliança das elites oriundas de mundos sociais diversos. Os discursos, tanto quanto as práticas sociais, são os produtos de instituições sociais. ${ }^{2}$

\section{A identidade, ainda ontem um conceito novo}

Ao lermos os trabalhos de Brubaker (2001), não podemos senão segui-lo quando denuncia a "capitulação" das ciências sociais diante do termo "identidade". Elaborando uma rápida história social da noção dos anos 1960 até os dias de hoje, para o caso americano, o autor sublinha a polissemia do termo, entre essencialismo e construtivismo. As ciências sociais parecem incapazes de conferir-lhe um sentido unificado.

Segundo Brubaker, a noção de identidade foi forjada nos Estados Unidos, nos anos 1960, notadamente em torno da obra A construção social da realidade, de Peter Berger e Thomas Luckman (1986 [1966]), e dos trabalhos de Erwin Goffman (1975 [1963]), ganhando, portanto, uma consonância construtivista e interacionista. A identidade é um construto, não um dado. No entanto, para além de uma exigência científica, a noção desenvolveu-se igualmente em um contexto político preciso, dominado pelas reivindicações identitárias (panteras negras etc.) que cristalizaram a noção. Para que a reivindicação que ela encarnava tivesse peso na cena pública, os usos comuns da noção de identidade constituíram um dado intangível, não negociável. Segundo esta compreensão da noção, não haveria um ator produtor da identidade. Ela simplesmente existiria, preexistindo aos atores, que são naturalmente seus portadores. Na linguagem corrente ou política, a identidade serviria para exprimir o que para si próprio ou para os outros é reivindicado como imutável (Hassenteufel 1991).

Poderíamos dizer o mesmo sobre a difusão do termo na França, desde os anos 1970, onde encontramos o mesmo conflito entre usos comuns e científicos da palavra identidade, entre essencialismo e construtivismo. Do lado do essencialismo e no contexto da renovação do regionalismo dos anos 1970, o termo foi empregado no sentido de trazer consigo uma "reivindicação de identidade" que denotasse a profundidade histórica da cultura regional, que precederia a cultura nacional, invertendo a hierarquia dominante das legitimidades culturais na França. Tais movimentos forjaram neologismos como a bretonidade (o fato de ser e de sentir-se bretão, região a oeste da França), cujo objetivo seria o de traçar uma fixidez de pertencimento, uma filiação histórica 
a mais longínqua possível, fazendo-a remontar ao pré-nacional. A noção serviu para os regionalismos bretão, basco ou corso, a expressar suas especificidades, afirmando uma cultura "mais verdadeira", mais autêntica, mais antiga, mais profunda que a "cultura nacional", desqualificada então como recente, artificial. ${ }^{3}$ No caso da imigração, encontramos o mesmo processo, por exemplo, com o termo "polonidade", contração de identidade polonesa empregada atualmente pelos descendentes inteiramente assimilados de uma imigração do período entre guerras, dos quais grande parte já não fala polonês - que procura atestar a continuidade das raízes polonesas, apesar de três ou quatro gerações nascidas na França (Lamarche 2005).

Desde o final dos anos 1970, Claude Lévi-Strauss reagiu a estas reivindicações identitárias regionalistas renovadas, referindo-se ao termo como "um modo pretensioso" e denunciando a "crise da identidade" da qual falava a "mídia". Mais do que recusar o termo que, na ocasião, não era ainda um conceito, o "seminário identidade" de Lévi-Strauss, publicado em 1977, pretendeu-se uma resposta aos ataques contra a etnologia, percebida pelos representantes regionalistas como uma colonização ideológica a aplainar as culturas. ${ }^{4}$ Entretanto, o seminário resultou em um impasse, como o mostra a definição não operacional de identidade proposta em sua conclusão, segundo a qual a identidade seria "Uma espécie de lar virtual ao qual devemos nos referir para explicar algumas coisas, mas que não tem existência real" (Lévi-Strauss 1977:332). A identidade tomada em seu senso comum foi então varrida pelos cientistas sem que um conceito fosse de fato forjado.

Desse modo, a formulação científica e a inclusão efetiva do termo nas ciências sociais francesas deram-se prioritariamente na sociologia e na etnologia, no início dos anos 1980. A noção foi consagrada pela utilização que dela fez Pierre Bourdieu, reagindo igualmente ao essencialismo dos movimentos regionalistas (Bourdieu 1980). O termo passou a designar, então, uma luta de poder na qual os diversos interesses agem, de maneira performativa, por intermédio das palavras, das categorias de pensamento sobre as fronteiras e os conteúdos dos grupos sociais. Os mecanismos e os agentes que, graças à sua posição em uma estrutura social, conseguem ao término da luta — constantemente renovável — impor ao grupo sua identidade dispõem da capacidade de fazer e desfazer os grupos.

No entanto, seria preciso completar esta história intelectual com uma história institucional das ciências sociais francesas para melhor compreendermos o entusiasmo científico pela noção de identidade. De fato, seu uso construtivista esteve no cerne de uma luta científica e institucional do início dos anos 1980. O termo "identidade" foi retomado pela nova Missão do Patrimônio Etnológico, criada em 1979 pelo Ministério da Cultura por 
iniciativa de Isaac Chiva, então diretor adjunto do Laboratório de Antropologia Social de Claude Lévi-Strauss, no intuito de modernizar a etnologia francesa, incorporando os aportes construtivistas da sociologia, particularmente aqueles de Pierre Bourdieu. O termo identidade constituiu uma das matrizes científicas da nova instituição, ${ }^{5}$ juntamente com "patrimônio", possibilitando uma releitura não essencialista do mundo rural. ${ }^{6}$

A Missão do Patrimônio Etnológico permitiu a um conjunto de jovens etnólogos, uma nova geração batendo às portas fechadas do CNRS — principal instituição de pesquisa antropológica na França (Rogers 2001), que recrutava muito pouco neste período - a obtenção de financiamento ou mesmo de empregos. Desta forma, ao obter financiamentos para trabalhos de campo na França, a Missão do Patrimônio Etnológico acabou por favorecer uma reconversão nacional dos etnólogos exóticos, ao que Herman Lebovics denomina a crise pós-colonial das ciências sociais francesas (Lebovics 2005). A instituição e seu modelo científico, impulsionado pelo sistema de editais, favoreceram um desenvolvimento dos estudos etnológicos sobre a França, na contracorrente do modelo classificatório e museográfico do Museu das Artes e Tradições Populares, na ocasião a principal instituição de etnologia da França. Desde sua fundação, em 1937, sob a égide da escola histórica dos Annales, da geografia vidaliana* e das sociologias durkheimianas que Georges-Henri Rivière tinha logrado agregar em torno de seu projeto, o Museu jamais encontrou plenamente seu lugar e sua legitimidade científica, comprometida pelos usos do folclore sob o regime de Vichy, perdendo assim sua legitimidade política e o suporte financeiro do Estado, impedindo-o de encontrar um segundo fôlego científico, levando-o a restringir-se a missões museográficas e classificatórias (Segalen 2005).

Para nos convencermos, vejamos antes de mais nada o que diz Claudie Marcel-Dubois, então presidente da Sociedade de Etnologia Francesa e pesquisadora no Museu de Artes e Tradições Populares, ao concluir o colóquio "Culturas populares", ocorrido em Nantes em 1984: "Convém apressar-se para estudar as culturas populares, já que suas especificidades logo serão apagadas pela estandardização e pela unificação dos comportamentos e dos hábitos" (Dubois 1984:104). Por intermédio da palavra "cultura",

\footnotetext{
* [N.T.] - Expressão que remete a Paul Vidal de la Blache, geógrafo francês considerado o fundador da moderna geografia francesa. La Blache defendia que o Estado deve planejar a apropriação de seu espaço geográfico considerando e conhecendo todas as características naturais e humanas de seu território. Suas idéias contrapunham-se às do geógrafo alemão Friedrich Ratzel, para quem a natureza determina as condições sociais, econômicas e tecnológicas de um povo.
} 
reencontramos os ecos da palavra "folclore" utilizada no pré-guerra (Laferté 2008). Estas noções de cultura, de comunidade, até então fartamente utilizadas em etnologia, encarnavam uma percepção rígida, unívoca, ruralista, material dos fenômenos de ordem cultural e levavam a crer na coerência dos grupos sociais delas portadores. "O etnólogo evidentemente notou as lacunas existentes nos textos do colóquio. Os planos da cultura tradicional camponesa e da cultura artesanal estão ausentes, em sua maioria. Sem querer fazer uma 'etnologia de vovô', tampouco devemos esquecer os aspectos da tradição" (Dubois 1984:104). A pesquisadora, que encarnava o modelo científico decadente do Museu Nacional das Artes e Tradições Populares, tentou uma vez mais reafirmar uma etnologia da França limitada ao estudo das tradições e culturas em vias de desaparecimento sob os golpes fatais da modernidade.

Do mesmo modo, a noção de identidade foi forjada contra uma sociologia marxista adepta do conceito de cultura, que em muitos aspectos revelou-se próxima a uma visão a-histórica das culturas (Verret 1988$)^{7}$ próprias a uma etnologia folclorizante. Assim, o colóquio "Culturas populares" foi uma iniciativa conjunta da Sociedade de Etnologia Francesa e da Sociedade Francesa de Sociologia, isto é, de seus respectivos presidentes, Claudie Marcel-Dubois e Michel Verret, cada um dos quais representando a etnologia folclorista e a sociologia marxista. Estas duas escolas foram alvo da mesma crítica:

A etnologia francesa talvez tenha ainda hoje dificuldade em ultrapassar sua total alergia ao tempo representado por um Van Gennep, ele que era, aliás, tão minucioso em termos de localização [...] Vocês me pareceram falar, tanto uns quanto outros (etnólogos e sociólogos), situarem-se em um hoje atemporal quando, na realidade, o leque das proposições recobria todo o século XX. A condição operária, por exemplo, não teria evoluído desde 1900 e não haveria um risco de anacronismo e de confusão ao se tratar a classe operária sem se precisar a qual período do século XX se está fazendo referência? (Lebrun 1984:101).

A crítica do historiador François Lebrun é pesada tanto para a etnologia quanto para a sociologia marxista. O conceito de cultura remete invariavelmente a uma visão homogeneizante e a-histórica dos mundos populares.

Em oposição a esta etnologia da França, ainda em 1984, por ocasião do colóquio "Etnologia francesa, Mitteleuropäische Volkskunde", ocorrido em Bad Homburg, Alain Morel, um dos jovens etnólogos, personagem central desta recente Missão do Patrimônio Etnológico, evocou a "problemática da identidade" (Morel 1987). Esperava-se dela que fosse capaz de libertar a etnologia do estudo dos mundos rurais e da tradição para abraçar temáticas 
urbanas e modernas, ao analisar as estratégias dos atores sociais diferenciados, deixando para trás uma percepção uniformizante da comunidade. "Culturas profissionais, culturas locais, culturas populares: já há algum tempo este antigo ordenamento mostrava suas falhas e sinalizava seus limites", escreveu na mesma direção Bernard Ganne (1984:376) por ocasião de um outro colóquio realizado em Montpellier, ainda em 1984, organizado pela Missão do Patrimônio Etnológico, sobre "Identidades locais e profissionais", demonstrando novamente o privilégio do termo "identidade" em detrimento do de "cultura" e encarnando em si próprio a passagem de gerações entre dois modelos científicos da etnologia francesa. O vocábulo "identidade" acompanhou a retirada da etnologia do que poderíamos chamar uma arqueologia social, uma visão tradicionalista dos mundos rurais eternos, para abrir a disciplina a objetos mais amplos, rompendo com o antigo recorte tradição / modernidade que recobria a divisão do trabalho científico entre etnologia / sociologia. ${ }^{8} \mathrm{O}$ termo "identidade" correspondeu à etnologia da França renovada, construtivista, sociológica, dos anos 1980 e 1990, contra a etnologia museográfica herdada de Georges-Henri Rivière (Gorgus 2003).

No início dos anos 1980, a palavra "identidade" passou a encarnar, em um mundo científico mais ou menos próximo a Pierre Bourdieu, uma renovação construtivista e historicista das ciências sociais. Os trabalhos de Anne-Marie Thièsse sobre as identidades regionais e nacionais, cuja matriz conceitual data desta mesma década, correspondem à plenitude dos ganhos heurísticos possibilitados pela noção. ${ }^{9} \mathrm{O}$ termo e a fórmula da "construção das identidades" inscreviam-se na linhagem de importantes autores anglo-saxões debruçados sobre a questão nacional, no quadro da revolução construtivista das ciências sociais em nível internacional. ${ }^{10}$ Trabalhando sobre as estratégias dos atores, sobre a produção de discursos sobre a região e a nação, Anne-Marie Thièsse, juntamente com outros (Bertho-Lavenir 1980; Guillet 1999; Martel 1992), demonstrou a historicidade de um modelo de produção cultural da nação datando do século XIX, modelo prioritariamente produzido em mundos eruditos (o "check-list"11 identitário composto por uma língua, uma bandeira, um folclore, uma música, uma gastronomia...). Mais ainda, o desenvolvimento de numerosos estudos comparativos na Europa, que colocaram em evidência um modelo que em tudo retomava os mesmos elementos, permitiu realçar a análise da especificidade de cada fato nacional. Anne-Marie Thièsse e outros se inscrevem numa linha de trabalhos que poderiam ser qualificados como história das representações nacionais, os quais, um século após os estudos de Michelet e Lavisse, obras fundadoras da história como produção cidadã da nação (Citron 1989), separaram definitivamente a escrita da história da nação do objetivo político de sua construção. 
Entretanto, essas apostas intelectuais que permitem compreender o rápido sucesso da noção de identidade — falar de identidade é localizar-se rapidamente do lado correto com relação à evolução da ciência, que relega ao purgatório cultura e comunidade - não livram o termo de sua indeterminação. Se a oposição entre senso comum e senso científico evidentemente obscurecia a noção, os usos científicos eram eles próprios pouco unificados. Em A identidade da França, Fernand Braudel (1986) reconvocou a palavra "identidade" para dizer, de modo inverso ao uso que dela fizeram Pierre Bourdieu e Anne-Marie Thièsse, que a França é um dado, uma permanência, um enraizamento. Os franceses e sua identidade não seriam senão seus ancestrais continuados. Fernand Braudel não forneceu, portanto, qualquer lugar à imigração nesta construção da nação. Gérard Noiriel, em uma postura construtivista igualmente inspirada pela compreensão bourdieusiana da noção, denunciou este uso reificado da palavra "identidade" (Noiriel 1988). Assim, a noção permaneceu excessivamente polissêmica no interior das ciências sociais, prestando-se a múltiplas interpretações equivocadas.

\section{A identidade, um conceito atualmente desgastado}

Para afastar-se do senso comum, para assegurar que as "identidades" sejam sempre um produto social e histórico - e poderíamos dizer o mesmo quanto às noções de tradição, de memória, de patrimônio... — uma das possíveis vias consiste em redinamizar as noções, inscrevendo-as diretamente em um processo. Muitos autores tomaram este caminho, ao integrar tais vocábulos canônicos em expressões como "política de memória" (L'Estoile 2001), de identidade, de tradição; "construção de identidades" (Thièsse 1999), "fábrica de lugares"; ${ }^{12}$ "empreendedor de identidade" (Saada 1993) ou de tradição, "produtor de tradições", de memórias; ou ainda o processo ganhando sentido pela incorporação de um sufixo que remete à idéia de patrimonialização (Rautenberg et alii 2000). Entretanto, estas expressões, ao nos livrarem de algumas dificuldades, criam novas, que poderíamos apresentar em três pontos: uma postura denunciatória, um desencantamento relativista, um obstáculo epistemológico. Parece, portanto, indispensável reintroduzirmos na análise a estrutura e a instituição social para que os excessos do construtivismo sejam contidos.

O construtivismo freqüentemente adota uma postura denunciatória. Ao falarmos de invenção das tradições, de construção das identidades, isto é, ao associar dois termos que fazem referência a dois registros separados o imutável, o espontâneo, o íntimo ou mesmo o sagrado para a identidade, a memória e a tradição, com o registro da construção, da invenção, da política, 
da fabricação - produz-se um choque entre os termos. Os dois registros estão comumente irremediavelmente separados, fazendo passar por "falsas" as identidades, as tradições, as memórias construídas pelas elites e analisadas pelo pesquisador. ${ }^{13}$ Dizer às pessoas pesquisadas que sua identidade é construída, fruto de uma estratégia, pode ser freqüentemente interpretado como um questionamento, como se sua identidade fosse uma impostura, uma vez que elas mesmas a percebem como natural.

De modo inverso, o pesquisador freqüentemente satisfaz-se rápido demais com uma fórmula que valoriza sua capacidade de desvendar um invisível social. Do mesmo modo, como tudo é "socialmente construído", nada é essencial, "inevitável", tudo é igualmente passível de desconstrução, de revisão (Hacking 2001). Ao nos impregnarmos da crença em um todo passível de desconstrução, ficamos impedidos de compreender aquilo que na atividade social é percebido como de ordem natural, o que é cristalizado. Nivelam-se assim as hierarquias inerentes ao social, perdendose em um desencantamento relativista no qual o social é destituído de sua rigidez, de sua coerção.

Parece portanto importante conter o construtivismo no domínio das estruturas sociais ${ }^{14}$ ou naquilo que Emile Durkheim chama de instituições sociais. ${ }^{15}$ Não se pode inventar tudo por toda parte e tão rapidamente. Por exemplo, a construção da identidade européia enfrenta a resistência das "identidades instituídas" a ela preexistentes (as identidades nacionais, os regionalismos, os comunitarismos, uma concepção republicana da nação, uma concepção comunitária da Nação...). Ou ainda o regionalismo na França teve de se bater contra as empresas concorrentes de ordenamento cognitivo da realidade social (uma leitura em termos de classe social trazida pelos sindicatos, ao longo do século XIX, ou ainda um centralismo modernizador por ocasião da Liberação...).

Do mesmo modo, seria preciso levar em conta a estrutura socioeconômica, a evolução das instituições políticas, as redes sociais, para que se possa mensurar as possibilidades de construção de uma imagem de um grupo, de um território. Nem tudo é passível de construção por toda parte com os mesmos custos de imposição, e são sobretudo as brechas nas instituições e nas estruturas sociais que revelam o jogo possível da construção discursiva e performativa do social. Seria preciso ainda examinar com precisão os mecanismos de prescrição, de inculcação dos discursos. É o que realiza Anne-Marie Thièsse (1997) em seu estudo da instituição escolar, Ils apprenaient la France; é igualmente o que faz Jean-François Chanet (1996). Infelizmente, todas as pesquisas que falam mecanicamente da "construção das identidades" nos dias de hoje limitam-se freqüentemente a uma análise dos discursos, a uma 
história das representações, e esta é a principal crítica que pode ser feita aos estudos sobre a criação das identidades nacionais. Retomando este modelo para o caso francês, basta analisar as categorizações das administrações, dos historiadores locais, dos geógrafos vidalianos ou dos guias turísticos para esboçar, por exemplo, as "identidades de país na Touraine dos séculos XVI ao XX". No entanto, qual seria a realidade de impregnação de uma imagem regional construída pelas elites junto às populações designadas?

Para reencontrarmos o rigor da análise, seria preciso portanto inventariar os sentidos da palavra "identidade". Foi o que fizemos, aliás, ao propormos três conceitos alternativos oriundos da literatura francófona das ciências sociais, com as noções de identificação, de imagem social e de pertencimento, que recobrem três processos sociais distintos (Bourdieu 1980). Para resumir aqui tal propósito, a identificação remete principalmente a um processo de classificação, de categorização dos indivíduos e dos grupos sociais por instituições sociais, no topo das quais se encontra o Estado contemporâneo. As identificações assim produzidas, sustentadas por uma administração e por técnicas (fichários, cédula de identidade, passaporte biométrico...), determinam categorias de direito: um nacional terá direito ao voto, mas um estrangeiro, não. A imagem social não tem a rigidez institucional da identificação e corresponde à produção, por alguns dos agentes dominantes, de símbolos homogeneizantes, de estereótipos que organizam a percepção dos territórios e dos grupos. De modo inverso, o pertencimento permanece como uma lógica do indivíduo ou, antes, da pessoa, cujas relações com um coletivo ou com um território são muito variáveis segundo suas múltiplas socializações. É somente na escala das práticas que se pode compreender como os identificados ou representados se apropriam, recusam ou aceitam as identificações e as imagens. A lógica de pertencimento segue sendo, em um dado espaço social ou territorial, a sociabilidade, os modos de inserção das pessoas nos diferentes grupos (família, amigos, sindicatos, empresa, grupo nacional...).

Neste quadro conceitual, evidentemente, os processos de folclorização da videira e a redefinição do marketing dos vinhos no período do entre guerras, na Borgonha, dizem respeito ao processo da imagem social. Tratase antes de mais nada, como veremos, de um folclore não orientado para as populações locais, mas para os jornalistas parisienses e internacionais. Trabalhar com as imagens sociais não é senão analisar a produção social dos discursos, de símbolos representando os grupos e os territórios, uma lógica da "publicidade" — no sentido de tornar público — com vistas à politização dos grupos e dos territórios. O termo "imagem", muito menos ambicioso que aquele de "identidade", não pretende de modo algum estudar a auto-definição, a auto-classificação das pessoas. A análise em meio às elites sociais sobre 
as relações de força para impor seu discurso, sua definição dos territórios e dos grupos sociais nada diz quanto à apropriação destes mesmos discursos pelas populações designadas, que remete então ao pertencimento.

Entretanto, analisar os discursos não significa, de modo algum, abandonar as instituições. Paralelamente a esta renovação conceitual, seria preciso também redirigir o olhar tanto para as estruturas quanto para os discursos, no intuito de se evitar o risco de uma visão excessivamente plástica da interiorização das normas sociais. A boa medida construtivista seria então um "construtivismo institucional e estrutural". É de algum modo ao que nos convidava Pierre Bourdieu (1980) quando se apressava em precisar que a análise dos discursos sobre a região só é pertinente se, por um lado, remetida à "autoridade social" do locutor e, por outro, à proximidade do discurso sobre o grupo com a "objetividade" política, econômica e social do próprio grupo.

Mesmo no tocante à análise dos discursos, seria preciso adotar um foco institucional tanto para compreender as possibilidades de êxito deste discurso - particularmente quanto à estrutura econômica e ao controle das instituições de representação dos territórios — quanto para determinar as operacionalizações destes mesmos discursos. Nós desejamos mostrar que a construção de uma imagem gastronômica para a região da Borgonha, no período do entre guerras, não é unicamente um efeito de discursos inventivos de empreendedores da imagem, de políticos ou eruditos. É também a conseqüência de uma infinidade de evoluções estruturais e institucionais que incluem a estrutura das redes parisienses e da notabilidade específica à burguesia da província; a ascensão de uma indústria alimentar de luxo modernizada; as reformas do sistema universitário; a organização política e a republicanização própria à III República. São estas instituições sociais muito amplas que tornam possível e exitosa a folclorização dos vinhos e dos vinhedos, uma prática social localizada, mas com aspiração internacional.

\section{Sociabilidade burguesa, comercialização e politização do território rural}

O mercado de vinhos da Borgonha passou, nos anos 1920, das mãos de comerciantes que propunham a marca privada como garantia de qualidade um mercado liberal, fundado sobre imagens aristocráticas das casas dos comerciantes (encenação de um castelo, da árvore genealógica, de brasões...) - a um mercado baseado em apelações de origem sob o controle dos proprietários. Localmente, esta mutação foi operada sobretudo graças à irrupção de um pequeno conjunto de novos atores que inventou tradições 
vinícolas, fazendo pender a imagem dos vinhos da Borgonha para aquela da qualidade vinhateira. No entanto, como para qualquer prática social, será preciso estudar a articulação de uma infinidade de mundos distintos, interdependentes, cada um dos quais animado por sua lógica própria, para compreender como esta reviravolta no controle e nas normas do mercado, inicialmente não programada e impensável, acabou sendo possível. Foi o que quisemos demonstrar no gráfico a seguir, retomando o que havíamos identificado quanto às relações sociais de interconhecimento ou à distância que tornam possível a ação final: a folclorização do vinhedo e a reviravolta do mercado. Duas escalas justapõem-se: uma primeira, local, regional; a segunda, nacional; diferentes mundos se cruzam, turísticos, jornalísticos, políticos, industriais, vinícolas, letrados e universitários. Para dar conta da constituição progressiva destas redes, retomemos cronologicamente as evoluções que ocorrem de Paris à Borgonha, articulando relações a longa distância com interações locais.

\section{Figura 1}

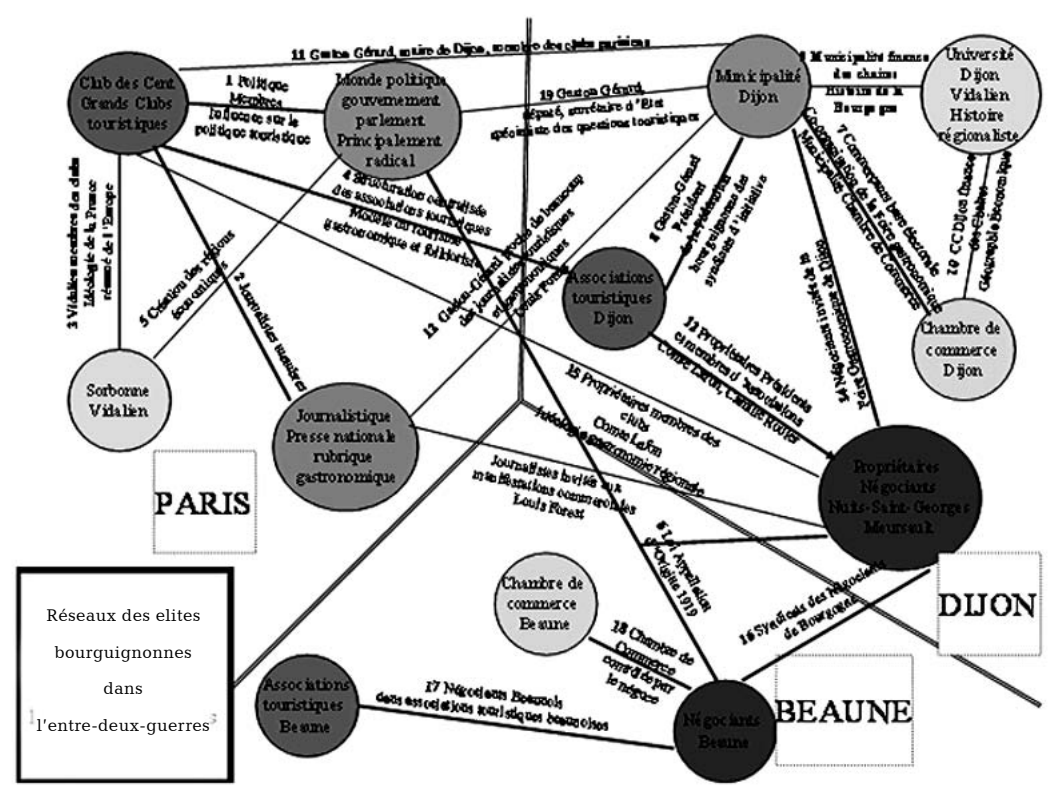




\section{Paris ou os mundos regionalistas modernizadores}

Um dos momentos fundadores de uma renovação dos objetos do turismo foi a criação, em 1913, do Clube dos Cem, um clube de automobilistas que reunia políticos de primeiro escalão - ministros, deputados, senadores, freqüentemente radicais ou republicanos de direita - (relação 1 no gráfico), jornalistas da imprensa nacional especializados em rubricas turísticas e gastronômicas (relação 2), industriais, homens da lei e artistas de envergadura nacional. O objetivo deste Clube era o de criar uma gastronomia regional para os "albergues" da província, capaz de seduzir os turistas. Tratava-se de conferir uma tonalidade interiorana e regional a pratos que se utilizavam de produtos locais, mas preparados segundo padrões burgueses, jogando com o exotismo da província e do rural para o homem urbano. O Clube dos Cem, composto por vários jornalistas da imprensa parisiense, beneficiouse de um amplo eco midiático que durou todo o período do entre guerras, ocasionando uma multiplicação de clubes gastronômicos à sua imagem, em Paris (Academia dos Gastrônomos, Clube dos Puros Cem, Clube dos Perdizes, Clube dos Gastrônomos Regionalistas...) e na burguesia das grandes cidades do interior (Clube dos Trinta, Clube Brillat Savarin, em Lyon, Bordeaux, Bruxelas...). Boa parte da inspiração deste turismo regional vinha da geografia vidaliana, da qual alguns dos representantes eram membros destes clubes. ${ }^{16}$ Em Dijon, Henri Hauser, um dos primeiros alunos de Vidal de la Blache, o fundador da moderna geografia na França, já ocupando um cargo na Universidade no período pré-guerra, é membro da seção Côte d'Or do Clube Alpino Francês (relação 3).

Enquanto até então dois elementos predominavam, desde antes da Primeira Grande Guerra, no conjunto do repertório turístico — a promoção dos sítios naturais e dos monumentos históricos — duas novas temáticas vieram agregar-se às anteriores: a da gastronomia regional e a do folclore, rapidamente difundidas após a reorganização dos mundos turísticos em torno de uma estrutura bastante centralizada - sobretudo a Federação Nacional dos Sindicatos de Iniciativa e a União Nacional das Associações Turísticas (relação 4).

No mesmo momento, o regionalismo econômico desenvolvido principalmente nos mundos turísticos ganhou igualmente terreno no espaço político e, como sempre, sobretudo junto ao movimento radical. Sendo assim, em 1917, Etienne Clémentel, ministro radical ${ }^{17}$ do comércio, lançou a idéia do recorte da França em regiões econômicas, fundadas sobre a base do reagrupamento voluntário das câmaras de comércio, contando com uma cidade-centro por região (Veitl 1992; Chatriot 2002). Tais reformas 
inspiraram-se nos trabalhos de Vidal de la Blache e foram instauradas no ministério por Henri Hauser (relação 5). Este regionalismo econômico de Estado pretendia-se modernizador, conciliando modernização econômica, afinada com o taylorismo e vinculação territorial. Este movimento era profundamente republicano, radical, tratando-se ao mesmo tempo de posicionar-se contra a direita política - ao favorecer as inovações econômicas e industriais, ratificando com isso uma aproximação ao radicalismo das elites industriais - mas igualmente contra os movimentos operários, ao propor uma modernização econômica da "justa medida": territorializada, distante das imagens da grande indústria. A questão regional aparecia como uma possibilidade de se refundar um radicalismo de terceira via, por oposição aos movimentos reacionários e ao socialismo.

Gaston-Gérard, o prefeito radical de Dijon, valeu-se então destes movimentos próximos ao radicalismo em escala nacional - a reconfiguração do turismo em torno da gastronomia regional e do folclore, o desenvolvimento de um regionalismo econômico - no intuito de assegurar seu poder local, tirando proveito de seu papel político clássico, de deputado prefeito na III República, papel de elo entre a escala nacional e a local, beneficiando a economia regional com os efeitos destas evoluções nacionais.

\section{A lei de 1919 ou a divisão proprietários/comerciantes}

Diversas evoluções importantes estavam simultaneamente em curso na economia vinícola, com a lei de 1919 sobre as apelações de origem, que fundou a denominação e a qualidade dos vinhos na origem geográfica das uvas. Esta lei foi o produto de uma nova correlação de forças nos vinhedos, em nível nacional. Em seguida a um importante movimento de sindicalização dos proprietários e dos vinhateiros (para a Borgonha, o movimento teve início já no final do século XIX, materializando-se em 1908, com a criação da Confederação Geral das Associações Vinícolas da Borgonha, união das federações departamentais dos sindicatos e associações vinhateiras) (Jacquet 2006), a representação dos proprietários e dos vinhateiros autonomizou-se dos comerciantes, anteriormente os notáveis da vinha. Esta republicanização do campo (Vigier 1991) trouxe consigo um número crescente de deputados favoráveis às causas da pequena propriedade, radicais e membros da SFIO (Seção Francesa da Internacional Operária, o partido socialista francês), nas cadeiras da Assembléia Nacional. Os comerciantes, os notáveis da vinha no século XIX, geralmente conservadores, perderam progressivamente o controle político dos vinhedos. No interior da SFIO, a política de defesa da pequena 
propriedade, iniciada em 1907 no Congresso de Nancy por Compère-Morel, permaneceu objeto de controvérsias, mas acabou prevalecendo. A SFIO e o partido radical arvoravam-se então como os maiores defensores da pequena propriedade, concebida como um modelo republicano de desenvolvimento rural, fundado sobre o pequeno proprietário livre, independente e não explorador, já que não empregando (senão raramente) mão-de-obra. Antes da Primeira Grande Guerra foram feitas emendas aos textos legais e, em 1919, foi votada uma lei favorável à pequena propriedade. Ao longo deste processo de democratização republicana do campo em torno do modelo artesanal, milhares de pequenos proprietários adquiriram um novo poder e passaram a ter mais peso político do que os grandes comerciantes e proprietários das "fábricas de vinho" da região do Midi. O critério da qualidade dos vinhos passou a ser, a partir de então, exclusivamente a origem geográfica da vinha, em detrimento da "marca" ou da "qualidade substancial" dos vinhos, os cavalos de batalha do antigo negócio.

Essa lei impôs severas dificuldades à Borgonha, onde, de modo distinto dos grandes vinhedos de Bordeaux, quase não havia monopólio, o que obrigava cada apelação a recorrer à Justiça para definir as fronteiras das áreas de apelação, como estipulado por lei. Os comerciantes que dominavam o mercado, representados pela Câmara de Comércio de Beaune e pelo sindicato dos comerciantes locais, tentaram preservar o sistema de equivalências e de misturas, ${ }^{*}$ isto é, um sistema que permitia atribuir o nome de um grande vinho a qualquer um que desenvolvesse as características gustativas de uma determinada apelação (relação 6). Um Volnay, neste sistema de equivalências, não é necessariamente um vinho colhido em Volnay, mas aquele que tem o gosto de um Volnay. Para tanto, os comerciantes compravam os vinhos no conjunto da Costa vinícola (sistema de equivalências sobre a Costa) e, se necessário, misturavam-nos com vinhos mais alcoolizados provenientes da Argélia ou do Languedoc para lhes dar sustentação e novamente obter as qualidades da apelação pretendida ("sistema de misturas"). Ao denunciar estas práticas, que progressivamente instauravam uma concorrência cada vez mais acirrada para os proprietários da Borgonha, os sindicatos de proprietários passaram a sistematicamente atacar os comerciantes, apoiando-se na lei de 1919 e, desse modo, multiplicando os processos, em meio a um clima deletério de suspeitas e fraudes. As aldeias de Meursault e NuitsSaint-Georges, dominadas não mais pelos comerciantes, mas por grandes

• [N.T.]. No original: système de coupage. Trata-se de uma mistura de vinhos de várias origens, com conotação negativa, praticada por comerciantes. 
proprietários-comerciantes, hesitaram por algum tempo (relação 16), mas acabaram por adotar uma atitude favorável às apelações de origem. Houve então uma ruptura entre, por um lado, os comerciantes de Beaune, com uma atitude tão mais agressiva quanto menos propriedades possuíam, e, por outro, os proprietários, dos quais os mais importantes tiravam proveito da lei de apelações de origem - proveito ainda mais valioso quando suas terras estavam localizadas no coração das apelações. Eles ganhavam, de fato, ao defenderem áreas de apelação super restritas, excluindo, sempre que possível, concorrentes quase sempre mais modestos, concentrados nas margens das grandes apelações. Diante desta multiplicidade de práticas e de normas em concorrência no mercado, a imagem de marca da Borgonha degradou-se rapidamente, nos anos 1920, com a multiplicação das fraudes, o consumidor não mais sabendo o que estava comprando por trás da etiqueta "Borgonha".

\section{Imagem gastronômica e novas alianças entre as elites de Dijon e vinícolas}

No momento em que a Costa vinícola digladiava-se a propósito das apelações de origem, Gastón-Gérard, eleito prefeito radical de Dijon em 1919, iniciou uma política que seguiu a trilha das evoluções assinaladas acima e levadas a cabo sobretudo por Etienne Clémentel, o ministro do comércio, radical, idealizador do regionalismo econômico. Apesar de Gaston-Gérard ser uma personalidade política claramente de esquerda no período pré-guerra (Jolly 1960-1977), ${ }^{18}$ a partir de 1919 ele se aproximou das elites econômicas e comerciais. Estas últimas compunham grande parte de sua lista municipal (relação 7) no contexto do Bloco Nacional (aliança das formações de direita) contra a ascensão da SFIO e as tensões políticas (multiplicação das greves em nível nacional, como em Dijon, cisão anunciada da SFIO com a criação do Partido Comunista Francês, em 1920). Gaston-Gérard inscreveu-se plenamente no deslocamento do radicalismo para a direita. Membro dos clubes turísticos locais, fundador e presidente da Federação dos Sindicatos de Iniciativa da Borgonha (relação 8), ele estava particularmente bem posicionado para mobilizar o repertório turístico, regionalista e a construção do território regional, um dos trunfos inovadores do radicalismo do pós-guerra.

No contexto da reforma Clémentel de criação das regiões econômicas, esta política municipal coincidiu com a criação da região econômica da Borgonha, centrada em Dijon. Graças às relações estabelecidas nos mundos industriais - que viram, neste período, o surgimento de industriais do ramo alimentar em Dijon: biscoitos, mostarda, chocolates, licores, pães de 
especiarias etc. - que controlavam a Câmara de Comércio da cidade, Gaston-Gérard aproveitou a oportunidade para unir suas habilidades e relações nos mundos turísticos e jornalísticos, no intuito de conduzir uma política de imagem da região construída em torno da nova indústria. Na ocasião, esta política seguiu duas orientações, misturando repertório turístico com conhecimentos oriundos das ciências sociais.

Em um primeiro momento, em 1921, ou seja, um ano após a criação da região econômica da Borgonha, a municipalidade e a Câmara de Comércio fundaram a Feira Gastronômica de Dijon. Todos os industriais do ramo alimentar da cidade a ela se associaram (relação 7). Ao propor a criação de pratos de gastronomia típica da região, esta feira, a primeira do gênero na França, alcançou muito rapidamente um enorme sucesso de público e de publicidade. Ao tornar-se a primeira materialização do discurso gastronômico regional, ela atraiu todos os jornalistas parisienses dos clubes gastronômicos, que reconheceram seu "universo de sentido gastronômico", afluindo a Dijon para celebrar a iniciativa. Gaston-Gérard tornou-se a coqueluche destes mundos jornalísticos parisienses, que o entronizaram, juntamente com o presidente da Câmara de Comércio de Dijon, no círculo fechado do Clube dos Cem (relação 11). O Clube, por sua vez, foi alçado a presidente de honra da feira, conduzindo toda a imprensa turística, gastronômica e parisiense para aquela cidade.

Em um segundo momento, a política da imagem gastronômica de Dijon, da municipalidade e da Câmara de Comércio passou igualmente pelo recrutamento de universitários, no intuito de legitimar o lugar ainda frágil da cidade como capital regional e gastronômica. Para tanto, graças à reforma da Universidade, que criou as cátedras regionais financiadas pelos poderes locais, a municipalidade recrutou um historiador regionalista, Gaston Roupnel (relação 9), encarregando-o de traçar a filiação gastronômica eterna da região e de Dijon.

A Câmara de Comércio financiou, ela mesma, a cátedra de um geógrafo vidaliano, Georges Chabot, que dirigiu os trabalhos sobre a Borgonha contemporânea, retomando todo o discurso dos poderes locais (relação 10) (Veitl 1993). O discurso regionalista apropriou-se da autoridade universitária, que se libertou, então, dos círculos restritos das sociedades científicas, aproveitando-se de uma reforma - a universidade regional permitiu a contratação de personalidades regionalistas com percursos atípicos, como Gaston Roupnel, ${ }^{19}$ por exemplo - ou permitindo a vinculação dos serviços de um universitário com percurso canônico como Georges Chabot (egresso da Escola Normal Superior, onde havia sido aluno de Vidal de La Blache) para beneficiar-se do programa da geografia vidaliana, fundada sobre a monografia regional, descrita como a ciência do governo regional. 
Desde o início da Feira Gastronômica, Gaston-Gérard tentou convencer os comerciantes de Beaune a dela participarem. Estes últimos recusaram a oferta por temerem a sombra que este evento projetaria sobre a venda de vinhos das Casas de Caridade de Beaune - verdadeira vedete comercial, o primeiro dia em que são provados os vinhos da safra anual, o dia de fixação das cotações do ano etc. - programada para alguns dias depois. Para melhor compreender esta recusa, acrescentemos que a burguesia de Beaune, composta basicamente por comerciantes, pouco freqüentava os círculos de Dijon, criando instituições específicas de sociabilidade, como uma Câmara de Comércio separada, seções do Clube Alpino Francês e do Automóvel Clube autônomas ${ }^{20}$ uma sociedade científica própria - a Sociedade de História e de Arqueologia de Beaune, igualmente pouco ligada aos mundos letrados de Dijon — seus filhos não freqüentando a Universidade da cidade, nem sua Escola de Comércio (relações 17 e 18). Houve, de fato, uma ruptura na burguesia regional de Beaune e Dijon. Gaston-Gérad convidou, então, os centros outsiders (Nuits-Saint-Georges, muito mais próximo a Dijon do que a Beaune e Mersault) para que expusessem na feira como convidados de honra. Relações de proximidade foram então estabelecidas com alguns dos grandes proprietários comerciantes da primeira cidade (sobretudo Camille Rodier e Georges Faiveley) e também da última (relação 14).

Em 1924, o Conde Lafon criou a Paulée de Mersault [uma festa anual que celebrava o fim da colheita]. Este último, proprietário por aliança de uma grande fazenda, presidente da Seção Côte d'Or e Morvan do Clube Alpino Francês (relação 13), amigo de Gaston-Gérard, com quem multiplicou as excursões turísticas (relação 14), importou, por sua vez, o modelo do folclore turístico, que dominava particularmente bem como experiente viajante dos Pirineus, região da qual trouxe material etnográfico para conferências que veio a realizar em Dijon. ${ }^{21}$ Para dar corpo à noção de "usos locais, leais e constantes" que alicerçou a lei de 1919, ele lançou mão, neste modelo folclórico, de elementos de uma imagem vinhateira e autêntica dos vinhos. Para tanto, reinventou completamente uma tradição, encenando a imagem do camponês idealizado pelos burgueses citadinos em busca do exotismo, a imagem da província desenvolvida no cerne da temática da gastronomia regional (Laferté 2003).

A partir de 1925, a Paulée de Mersault, reunindo sobretudo os proprietários favoráveis às apelações, obteve rápido sucesso graças à presidência de Gaston-Gérard e à vinda de jornalistas parisienses integrantes de sua rede. $\mathrm{O}$ Conde Lafon tornou-se um convidado de honra habitual das personalidades do Clube dos Cem (relação 15), que fizeram dele o campeão da boa bebida, do bom produto da Borgonha. Neste mesmo sentido, a Revista do Vinho da 
França, igualmente próxima da temática regionalista, aplaudiu os esforços deste novo marketing tradicionalista, percebido como o meio de destronar os comerciantes, já completamente desacreditados devido às fraudes nas apelações. A Revista do Vinho da França, criada em 1933, uniu a Paulée de Paris à imagem daquela de Mersault para tentar alavancar as vendas em torno do imaginário do vinhedo e do proprietário guardião da qualidade, contra a imagem aristocrática dos vinhos da Borgonha, marketing oriundo do século XIX, época áurea dos comerciantes.

Este período, compreendido entre 1925 e 1935, correspondeu ao apogeu político de Gaston-Gérard, que se tornou deputado e, em seguida, secretário de Estado, encarregado sobretudo das questões relativas ao turismo e à publicidade (relação 19). Gaston-Gérard foi uma das grandes personalidades dos mundos turísticos e publicitários, que desenvolveu significativamente estas redes de influência. Em contrapartida, ele beneficiou as redes locais estruturadas em torno da Câmara de Comércio e dos grandes proprietários e comerciantes da Costa de Nuits e de Mersault. Estas estratégias distintivas de proprietários dos centros concorrentes de Beaune levaram a uma progressiva ruptura dos laços entre os negócios de ambas as cidades (relação 15), anteriormente estruturados ao redor do sindicato dos comerciantes. Os nativos de Nuits eram proprietários comerciantes, ao passo que aqueles de Beaune, que controlavam as instituições de representação do negócio (Câmara de Comércio, Sindicato dos Comerciantes da Borgonha - relação 18), eram antes de mais nada comerciantes com propriedades limitadas.

Tais estratégias tornar-se-ão ainda mais visíveis em 1929, quando se desencadeia a crise econômica, percebida sobretudo como comercial, crise esta particularmente precoce para os grandes vinhos produzidos para exportação. Para reagir a ela, os proprietários e comerciantes tentaram desenvolver uma campanha publicitária coletiva, segundo os cânones do que então se denominava "publicidade redacional"." A iniciativa coube aos comerciantes de Nuits, mais próximos dos mundos jornalísticos parisienses desde a intermediação de Gaston-Gérard, mas também com melhor formação, sobretudo na Escola de Comércio de Dijon, um dos primeiros lugares na França a oferecer formação nas novas técnicas publicitárias, tendo se beneficiado do papel pioneiro de Gérard, uma das personalidades da difusão de técnicas publicitárias na França e fundador de uma comissão de publicidade e propaganda coletiva na Assembléia Nacional (relação 15).

• [N.T.]. Publicidade redacional nada mais é do que a publicação de matérias pagas por veículos da imprensa. 
A publicidade redacional consiste na compra de jornalistas e de artigos de informação gerais visando à promoção de um produto de luxo (Chessel 1998). ${ }^{22}$ Muito rapidamente, no entanto, diante dos custos elevados destes releases, os proprietários e comerciantes abandonaram o projeto publicitário.

Logo, a partir de 1933 o imperativo publicitário se fará mais urgente, com o fim anunciado da proibição aos Estados Unidos abrindo perspectivas de reconquista comercial. A resposta dos comerciantes e proprietários de Nuits deu-se no sentido de retomar o caminho aberto pela Paulée de Mersault, sistematizando-o. Em 1934, eles criaram a Confraria dos Cavalheiros do Tastevin* de Nuits-Saint-Georges. Esta tradição vinícola inventada inscreveu-se nos moldes da gastronomia regional, com a encenação da aldeia eterna com vinhateiros autênticos, encenação esta que imediatamente obteve um grande sucesso midiático, com a vinda de jornalistas parisienses, americanos, ingleses, belgas, suíços... uma vez mais, graças à rede de Gaston-Gérard (Laferté 2005).

Este modelo de marketing tradicionalista, "o novo certificado da qualidade", como ressaltou L'Illustration ${ }^{23}$ institucionalizou-se progressivamente. Em 1935, a lei das Apelações de Origem Controladas foi votada, sendo instituído o CNAO (Centro Nacional das Apelações de Origem), que retomou o modelo dos "usos locais, leais e constantes". Para os vinhos de alta qualidade, desenvolveu-se o engarrafamento e a venda direta na propriedade. O proprietário tornou-se garantia de qualidade. Em 1937, por ocasião da Exposição Internacional de Paris, o Pavilhão da Borgonha foi construído à semelhança da Confraria dos Cavalheiros do Tastevin, encenando, em uma adega modernizada, os atributos do vinhedo, os tonéis, os instrumentos da vinha, o avental etc. A imagem da Borgonha será, dali por diante, a de uma região gastronômica e vinhateira mais do que aristocrática. Champagne e Bordelais, tendo iniciado suas trajetórias de marketing mais cedo, permaneceram como duas regiões vinícolas mais fortemente marcadas pelo repertório do século XIX, um modelo aristocrático.

\section{Conclusão}

A difusão de uma imagem tradicionalista no marketing de vinhos e de produtos alimentares de luxo não é, de modo algum, produto de um pertencimento

\footnotetext{
• [N.T.]. A expressão remete ao ato de provar os vinhos para certificar-se de que atendem às
} exigências de qualidade para a obtenção da apelação Borgonha. 
social, o prolongamento de uma sociabilidade vinhateira ou própria da Borgonha, mas, antes, o produto da luta política e comercial para se impor uma imagem sedutora dos vinhos a uma clientela nacional e internacional. Para constituir esta nova veia do marketing dos vinhos em um lugar específico, a Borgonha, diversos mundos e instituições sociais foram mobilizados.

A partir de instituições estabilizadas da sociabilidade local (Câmara de Comércio, municipalidade, sociedades científicas, clubes turísticos etc.) e beneficiando-se de novas (universidades regionais, região econômica, Escola de Comércio), constitui-se, em Dijon, uma aliança no seio das elites locais em torno do prefeito radical, Gaston-Gérard, e da questão territorial e regional, aliança à qual se associou parte dos proprietários vitícolas, membros desta burguesia de Dijon (Laferté 2004).

Estas novas alianças mobilizaram as elites políticas, econômicas, universitárias modernizadoras e desenharam novas redes locais, para além dos notáveis tradicionais do século XIX (Halevy 1930) ou das redes socialistas que permeavam os mundos sindicais e as experiências de socialismo municipal (Dogliani 1991; Lefebvre 2001). Entretanto, tais alianças entre as elites locais foram, em alguma medida, elaboradas e tornadas possíveis pelas evoluções nacionais, ocorridas em Paris desde as vésperas da Primeira Guerra, no seio de um outro meio burguês, aquele dos jornalistas e dos clubes gastronômicos, cujas temáticas foram, em seguida, retransmitidas aos ministérios e à Assembléia Nacional.

Esta preparação prévia das recomposições locais em certa medida garantiu a eficácia social, já que se beneficiou de alguns "laços fracos" (Granovetter 2000 [1973]) unindo Dijon a Paris, os empreendedores modernizadores da região da Borgonha aí encontrando a ocasião para um suporte e um poder de reviravolta inimaginável, se levarmos em conta simplesmente as correlações de força econômicas locais. Com efeito, de início, os comerciantes dominavam o conjunto do filão vitícola graças ao controle completo da comercialização, da rotulação dos vinhos nas redes comerciais, ao quase monopólio do aparato de vinificação - pois a maioria dos proprietários vendia suas uvas ao comércio - e às fortunas de família, em um mundo caracterizado quase exclusivamente pelo auto-financiamento. Eles seriam finalmente destituídos pela propriedade, que passou a beneficiar-se de um trabalho de representação política autonomizada.

A criação de tradições para usos econômicos é, portanto, o produto de mundos interdependentes. As ações dos atores irão finalmente conduzir a uma mudança social com interações de uns sobre os outros, não mais em relações face a face, mas à distância, segundo procedimentos mediados por coerções, no contexto daquilo que Durkheim denomina instituições sociais. 
Para ilustrar esta interdependência social, para fins do nosso estudo, parece evidente que, no período do entre guerras, a possibilidade vislumbrada pela municipalidade de Dijon de produzir uma história regional legitimada pelas universidades locais dependeria da lei de reforma universitária, de 1896, que permitiu a criação das cátedras universitárias financiadas pelos poderes locais e, em seguida, pelo desenvolvimento do turismo e do regionalismo econômico iniciado a partir de Paris.

Ou ainda, o marketing dos vinhos fundado sobre a imagem da aldeia foi, em parte, uma conseqüência da ideologia republicana da III República, a defesa do pequeno proprietário como argumento de republicanização dos campos. Nestas diversas ações, muito poucas pessoas não estão diretamente ligadas, a ação dos primeiros dependendo, ao mesmo tempo, das conquistas históricas precedentes e das ações concomitantes dos contemporâneos. É fundamentalmente a imprevisibilidade prévia da junção das histórias e dos mundos sociais posteriormente observados que deixa em aberto a multiplicidade dos possíveis de um determinado tempo histórico.

Este modelo de marketing dos vinhos da Borgonha fez escola na Liberação para alcançar o conjunto da economia alimentar de luxo: um bom produto deve ser da terra, tradicional. É exatamente este marketing tradicionalista que é retomado pelos vinhedos que desejam adotar uma trajetória de qualidade. Esta última foi instituída na França em torno de uma demanda pela apelação de origem e pela criação de festividades folclóricas, como analisado por Marie-France Garcia para o caso de Chinon e por Philippe Chaudat para os vinhos de Arbois ou, ainda, por Ali Aït Abdelmalek ${ }^{24}$ para um outro produto alimentar de luxo que não o vinho, a andouille.*

Não menos do que cem confrarias podem ser contadas em 1970, criadas segundo o modelo da Confraria dos Cavalheiros do Tastevin, e há oitocentas, atualmente, recobrindo o conjunto dos produtos alimentares desejosos de adotar uma trajetória de qualidade. Só muito recentemente esta trajetória tradicional da qualidade francesa vai perder terreno, pressionada pela concorrência internacional, que difunde um modelo alternativo, mais tecnológico, em torno da noção de cepagem, em detrimento daquela de origem, estudada por Marie-France Garcia-Parpet (2001, 2004). A importação deste modelo concorrente, particularmente no Languedoc, faz-se então por

• [N.T.] - Uma espécie de morcela, embutido à base de vísceras de porco ou de bezerro cortadas em tiras e inseridas em uma parte do intestino grosso, que se come frio. 
outsiders, que tentam alterar os critérios de definição da qualidade, para modificar a institucionalização do mercado, abandonando completamente os AOC no intuito de estabelecer uma nova hierarquia de preços.

Recebido em 20 de dezembro de 2007

Aprovado em $01^{\circ}$ de maio de 2008

Traduzido por Roberta Ceva

Gilles Laferté é pesquisador no INRA e CESAER, em Dijon e no CMH e Ecole d'Economie de Paris. E-mail: <laferte@enesad.inra.fr> 


\section{Notas}

${ }^{1}$ Para os resultados do conjunto da pesquisa, ver Laferté (2006).

${ }^{2}$ Ao desenvolver neste artigo nossa insatisfação com a noção de identidade através de sua história crítica nas ciências sociais francesas, tratamos, em um segundo momento, de aplicar para nós mesmos a discussão conceitual levada a cabo em Avanza e Laferté (2005).

${ }^{3}$ Para encontrar a retórica do período sobre a identidade regional, ver particularmente Morvan Lebesque (1970). Ver igualmente a onipresença continuada do termo "identidade" na literatura bretã recente, como por exemplo em Treguer (2004).

${ }^{4}$ Ver o prefácio de Lévi-Strauss (1977).

${ }^{5}$ Sobre o lugar das noções construtivistas de patrimônio e identidade na Missão do Patrimônio Etnológico, ver Laferté e Renahy (2003a), seguido da réplica de Micoud et alii (2003) e pela tréplica.

${ }^{6}$ Um dos primeiros editais (1982 a 1985) lançado pela nova instituição criada por Isaac Chiva intitulou-se "Identidades sociais, identidades territoriais". Ver Terrain, n. 5, 1985.

${ }^{7}$ Citemos a conclusão (p. 275) desta obra para evidenciar o essencialismo que prevalece nesta sociologia, hoje em dia completamente em desuso: "Homens com nome de campo: camponeses. Com nome de arte: artesãos. Com nome de obra: operários. Os primeiros mais próximos aos campos. Estes últimos, mais próximos ao fogo: ao lar (melhor dizendo) de todas as culturas possíveis, já que é com este mesmo fogo que se esquentarão todas. [...] As classes nascem, as classes morrem. Morrendo aqui, thes ocorre de renascer alhures. OU não: elas estão mortas. E aí é com você, 'camarada historiador'. Mas as culturas jamais morrem de fato, já que trazem consigo uma questão que as ultrapassa. E elas sobrevivem assim às classes, aos povos, aos próprios Povos que foram seus portadores. Na memória, ou somente na história. Como a fonte diz ao rio: agora é com você, camarada rio... Boa sorte, camarada operário...".

${ }^{8}$ Encontramos a mesma crítica construtivista, igualmente próxima da matriz bourdieusiana, desta divisão científica em Grignon e Weber (1993).

${ }^{9}$ Ver, por exemplo, a decadência dos trabalhos sobre o regionalismo, como por exemplo o colóquio "Região e regionalismo na França: do século XVIII aos dias de hoje", organizado pelo grupo de pesquisas em história moderna e pelo centro de pesquisas sobre as sociedades contemporâneas da Faculdade de Ciências Históricas da Universidade das Ciências Humanas de Estrasburgo, ocorrido de 11 a 13 de outubro de 1974.

${ }^{10}$ Ver, particularmente, os trabalhos de Benedict (1996 [1983]); Gellner (1983); Hobsbawm e Ranger (1983). 
${ }^{11}$ Expressão tomada de empréstimo do sociólogo sueco Orvar Löfgren (1989).

12 Ver Genèses, n. 40, intitulado "Fábrica de lugares".

${ }^{13}$ É exatamente a mesma constatação que encontramos em Cavazza (2003).

${ }^{14}$ A noção de estrutura remete mais especificamente à hierarquia social, aos posicionamentos, à detenção de propriedades sociais, de grupos sociais e de indivíduos.

${ }^{15}$ As instituições sociais são ao mesmo tempo relações sociais tornadas rígidas em uma organização, mas de modo mais geral, laços sociais, universos de representação, disposições cristalizadas que se impõem aos indivíduos.

${ }^{16}$ Esta questão é amplamente explorada em Bertho-Lavenir (1999). Nesta mesma direção, ver também Baudelle et alii (2001).

${ }^{17}$ O radicalismo na França tem um peso político considerável na III República, que desenvolve um programa republicano, laico, social, de defesa dos pequenos e de proteção estatal dos cidadãos. A emergência de uma esquerda mais reivindicativa, socialista e, em seguida, comunista desloca progressivamente os radicais em direção ao centro do tabuleiro político.

${ }^{18}$ Para uma abordagem mais geral sobre a situação política da Borgonha no período, consultar Levêque (1978).

${ }^{19}$ Gaston Roupnel não era ex-aluno da Escola Normal Superior, cujos egressos ocupavam, em 1910, 80\% dos cargos universitários. Também não tinha a aggregation — na época, uma diplomação obrigatória para qualquer cargo universitário na França — nem qualquer publicação científica reconhecida no momento de sua contratação. Possuía, no entanto, uma reputação sólida como escritor regionalista, com vários romances de sucesso.

${ }^{20}$ Duas associações canônicas de lazer das classes altas francesas da época, a primeira desenvolvendo inicialmente a prática de alpinismo, em seguida, abrindose a todas as atividades turísticas; a segunda, mais orientada para o lazer ligado ao automobilismo.

${ }^{21}$ Ver, por exemplo, Lafon $(1911,1913)$.

22 Para alguns exemplos das campanhas idealizadas para os vinhos, ver Chevrier (1933); Baudoin (1928, 1930); Mathieu (1930); Farge (1929, 1930).

23 "A elegância dos discursos, o tom da cerimônia e das palavras trocadas revelam uma medida, um tato, um gosto especificamente francês. Celebram-se as virtudes de nossa raça e de nossa terra e, evocando o passado, preparamos o futuro. O Tastevin crescerá. Ele ultrapassará os limites de sua província, se espalhará por toda a França vinícola e contribuirá sem dúvida para fundar este certificado de vinhos que defenderá nossos vinhedos e nossas cavas contra os malfeitos e as fraudes. É preciso louvar 
M. M. Faiveley e Rodier, do sindicato de Nuits, por terem fundado uma confraria, digna irmã das camaradagens e das corporações de outros tempos." E, para concluir "O tempo do Temerário está esquecido; hoje, é a Borgonha que conquistou a França. Que digo eu? Foi o mundo que ela anexou!" (Cadhilac 1934:554-555).

${ }^{24}$ Para o caso do vinho, ver, por exemplo, Chaudat (2003); para outros produtos alimentares, ver Abdelmalek et alii (2001). 


\section{Referências bibliográficas}

ABDELMALEK, Ali Aït; CHAUVIGNÉ, Christian. 2001. "'Faire l'andouille à Guéméné'. La confrérie des 'goustiers de l'andouille' entre marketing et célébration identitaire". Ruralia, 8:121-140.

AVANZA, Martina; LAFERTÉ, Gilles. 2005. “Dépasser la 'construction des identités'? Identification, image sociale, appartenance". Genèses, 61:154-167.

BAUDELlE, Guy; OZOUF, Marie-Vic; ROBIC, Marie-Claire (orgs.) 2001. Géographes en pratique (1870-1945). Le terrain, le livre, la cité. Rennes: Presses Universitaires de Rennes.

BAUDOIN, Raymond. 1928. "La Bourgogne et ses vins". Revue du Vin de France, set:3-5.

- 1930. "Résoudre la crise par la propaganda". Revue du Vin de France, jan:1-9.

BENEDICT, Anderson. 1996. L'imaginaire national. Paris: La Découverte.

BERGER, Peter; LUCKMANN, Thomas. 1986. La construction sociale de la réalité. Paris: Meridiens.

BERTHO-LAVENIR, Catherine. 1980. "Linvention de la Bretagne. Genèse sociale d'un stéréotype". Actes de la Recherche en Sciences Sociales, 35:45-62.

- 1999. La roue et le stylo, comment nous sommes devenus touristes. Paris: Odile Jacob.

BOURDIEU, Pierre. 1980. "L'identité et la répresentation. Eléments pour une réflexion critique sur l'idée de région". Actes de la Recherche en Sciences Sociales, 35:63-72.

BRAUDEL, Fernand. 1986. L'identité de la France. Tomos I, II, III. Paris: ArthurFlammarion.

BRUBAKER, Rogers. 2001. "Au delà de l'identité". Actes de la Recherche en Sciences Sociales, 139:66-85.
CADHILAC, Paul-Emile. 1934. L'Illustration, 15:554-555.

CAVAZZA, Stefano. 2003. "Territoire et identité". Études Rurales, 163164:109-131.

CHANET, Jean-François. 1996. L'école républicaine et les petites patries. Paris: Aubier.

CHATRIOT, Alain. 2002. "Les 'régions économiques' d'une guerre à l'autre: aménagement du territoire, discours, projets et pratiques". In: P. Caro; O. Dard; J. C. Daumas (orgs.), La politique d'aménagement du territoire: racines, logiques et résultats. Rennes: Presses Universitaires de Rennes. pp. 53-64.

CHAUDAT, Philippe. 2003. Les mondes $d u$ vin. Ethnologie des vignerons d'Arbois. Paris: L'Harmattan.

CHESSEL, Marie-Emmanuelle. 1998. La publicité, naissance d'une profession, 1900-1940. Paris: Éditions du CNRS.

CHEVRIER, Félix. 1933. "L'oeuvre de propagande vinicole française". Revue du Vin de France, jan:10.

CITRON, Suzanne. 1989. Le mythe national. L'histoire de France en question. Paris: Les Éditions Ouvrières.

DOGLIANI, Patricia. 1991. Un laboratoire de socialisme municipal: France, 18801920. Tese de doutorado em história contemporânea, Université Paris X.

DUBOIS, Claudie Marcelle. 1984. "Conclusion". Les cultures populaires, introductions et synthèses. Colloque à $\mathrm{l}^{\prime}$ Université de Nantes, 9-10 juin. Ms.

FARGE, André. 1929. "Une campagne de publicité vinicole". Revue du Vin de France, ago:7-8.

. "Un plan de publicité pour augmenter la consommation du vin". Revue du Vin de France, jan:9-11. 
GANNE, Bernard. 1984. "Identité locale, identité professionnelle". Sociologie $d u$ Sud-Est, 41-44:1-381. Colóquio "Identité locale, identité professionnelle", Montepellier, 7-9 novembro 1984.

GARCIA-PARPET, Marie-France. 2001. "Le terroir, le cépage et la marque: stratégies de valorisation des vins dans un contexte de mondialisation". Cahiers d'Economie et de Sociologie Rurales, 60-61:149-180.

. 2004. "Le marché de l'excellence: le classement des grands crus à l'épreuve de la mondialisation". Genèses, 56:72-96.

GELLNER, Ernest. 1983. Nations and nationalism. Ithaca: Cornell University Press.

GOFFMAN, Erwin. 1975. Stigmate. Les usages sociaux des handicaps. Paris: Minuit.

GORGUS, Nina. 2003. Le magicien des vitrines. Le muséologue Georges-Henri Rivière. Paris: Éditions de la MSH.

GRANOVETTER, Mark. 1973. "The strength of weak ties". American Sociological Review, 78(6):1360-1380. - 2000. Le marché autrement. Paris: Desclée de Brouwer.

GRIGNON, Claude; WEBER, Florence. 1993. "Sociologie et ruralisme, ou les séquelles d'une mauvaise rencontre". Cahiers d'Economie et Sociologie Rurales, 29:59-74.

GUILLET, François. "Naissance de la Normandie (1750-1850). Gênese et épanouissement d'une image régionale". Terrain, 33:145-156.

HACKING, Ian. 2001. Entre science et réalité. La construction sociale de quoi? Paris: La Découverte.

HALEVY, Daniel. 1930. La fin des notables. Paris: Grasset.

HASSENTEUfEL, Patrick. 1991. "Pratiques representatives et construction identitaire". Revue Française de Science Politique, 41(1):6-25.
HOBSBAWM, Eric; RANGER, Talcot. 1983. The invention of tradition. Cambridge: Cambridge University Press.

JACQUET, Olivier. 2006. Les syndicates vitivinicoles en Bourgogne de 1884 à la mise en place des AOC. Tese de doutorado em história, Université de Dijon.

JOLLY, Jean (org.) 1960-1977. Dictionnaire des parlementaires français. Notices biographiques sur les ministres, deputes et sénateurs français de 1889 à 1940. 8 vol. Paris: PUF.

LAFERTÉ, Gilles. 2003. “La mise en folklore des vins de Bourgogne: la Paulée de Meursault". Ethnologie Française, 3:435-442. . 2004. "L'homme politique, l'industriel et les universitaires: alliance à la croisée du régionalisme dans l'entredeux-guerres". Politix, 67:45-69. . 2005. "Un 'folklore' pour journalistes: la Confrérie des Chevaliers du Tastevin". Ethnologies Comparées, 8 (http:// alor.univ-montp3.fr/cerce/r8/n.8.htm.) - 2006. La Bourgogne et ses vins: image d'origine contrôlée. Paris: Belin. - 2008. "Tensions et catégories du folklore en 1937: folklore scientifique, folklore appliqué, folklore touristique et commercial". In: Du folklore à l'ethnologie. Institutions, musées, idées en France et en Europe de 1936 à 1945. Paris: MSH. No prelo.

. \& RENAHY, Nicolas. 2003a. "Campagne de tous nos désirs... d'ethnologues". L'Homme, 166:225-234.

. 2003b. "L'ethnologue face aux usages sociaux de l'ethnologie". L'Homme, 166:239-240.

LAFON, Jules. 1911. "L'Andorre à dos de mullet". Bulletin de la Section Côte d'Or et Morvan du Club Alpin Français, 22:15-34.

- 1913. "Mes Pyrénées". Bulletin de la Section Côte d'Or et Morvan du Club Alpin Français, 24.

LAMARCHE, Karine. 2005. La polonité au croisement des appartenances. L'exem- 
ple del'association folklorique Kalina de Courcelles-lès-Lens. Memória de DEA em ciências sociais. Paris, EHESS.

LEBESQUE, Morvan. 1970. Comment peut-on être breton? Paris: Seuil.

LEBOVICS, Herman. 2005. "On the origins of the mission du patrimoine ethnologique". Ethnologies Comparées, 8 (http://recherche.univ-montp3. fr/cerce/r8/h.l.htm).

LEBRUN, François. 1984. "Conclusion". Les cultures populaires, introductions et syntheses. Colloque à l'Université de Nantes, 9-10 juin. Ms.

LEFEBVRE, Remi. 2001. "Subversion et apprentissage des règles du jeu institutionnel". Politix, 53:87-116.

L'ÉSTOILE, Benoît de. 2001. "Le gout du passé". Terrain, 37:123-138.

LEVÊQUE, Pierre. 1978. “Du second Empire à la Vème Republique". In: J. Richard (org.), Histoire de la Bourgogne. Toulouse: Privat. pp. 385-402.

LÉVI-STRAUSS, Claude. 1977. L'identité, séminaire interdisciplinaire. Paris: PUF.

LÖFGREN, Orvar. 1989. "Nationalization of culture". Ethnologica Europea, XIX(1):5-25.

LYNCH, Edouard. Moissons rouges: les socialistes français et la société paysanne durant l'entre-deux-guerres, 1918-1940. Villeneuve-d'Ascq: Presses Universitaires du Septentrion.

MARTEL, Philippe. 1992. "Le félibrige". In: P. Nora (org.). Les lieux de mémoires. Tomo III. pp. 567-711.

MATHIEU. 1930. "La propagande du vin". Revue du Vin de France, out:18-24.

MICOUD, André; BÉRARD, Laurence; MARCHENAY, Philippe; RAUTENBERG, Michel. "Et si nous prenions nos desires en compte?". L'Homme, 166:235-238.

MOREL, Alain. 1987. "Nouveaux terrains, nouveaux problèmes". In: Isaac Chiva \& Utz Jeggle (orgs.), Ethnologies en miroir, la France et les pays de langue allemande. Paris: MSH. pp. 151-171.
NOIRIEL, Gérard. 1988. "Le creuset français". Histoire de l'immigration - XIXeXXe siècle. Paris: Seuil. pp. 50-67.

Terrain, n. 5 "Identité culturelle et appartenance régionale", 1985.

RAUTENBERG, Michel; MICOUD, André; BÉRARD, Laurence; MARCHENAY, Philippe. 2000. Campagnes de tous nos désirs. Patrimoine et nouveaux usages sociaux. Paris: Maison de la Science de L'Homme.

ROGERS, Susan Carol. 2001. "Anthropology in France". Annual Review of Anthropology, 30:481-504.

SAADA, Emmanuelle. 1993. "Les territories de l'identité. Etre juif à Arbreville". Genèses, 11:111-136.

SEGALEN, Martine. 2005. Vie d'un museé. Paris: Stock.

SCHWEITZ, Daniel. 2001. Histoire des identités de pays en Touraine (XVIXXè siècle). Aux origines de la France des pays. Paris: L'Harmattan.

THIÈSSE, Anne-Marie. 1997. Ils aprennaient la France: l'exaltation des régions dans le discours patriotique. Paris: Éditions de la Maison des Sciences de L'Homme.

- 1999. La création des identités nationales. Europe, XVIII-XXème siècle. Paris: Seuil.

TREGUer, Michel. 2004. Arborigéne occidental. Paris: Fayard/ Mille et Une Nuit.

VEITL, Philippe. 1992. Les regions économiques. Clémentel et l'invention de la région des Alpes françaises. Tese de doutorado em ciências políticas, Grenoble. . 1993. "Un géographe engagé. Raoul Blanchart et Grenoble, 1910-1930". Genèses, 13:98-117.

VERRET, Michel. 1988. La culture ouvrière. Saint-Sébastien: ACL.

VIGIER, Philippe. 1991. "La République et les paysans". Politix, 15:7-11.

WEBER, Florence. 2000. “Le folklore, l'histoire et l'Etat en France (1937-1945)". Revue de Synthèse, 3-4:453-467. 
Resumo

A partir de uma história dos usos da noção de identidade, na França, pode-se isolar uma compreensão essencialista própria ao senso comum e a alguns trabalhos de ciências sociais e uma outra, construtivista, que se impôs amplamente nas ciências sociais contra a noção de cultura, consagrando a fórmula hoje corriqueira da construção de identidades. Parece-nos que os ganhos heurísticos trazidos pela fórmula estão atualmente esgotados, já que tendem a privilegiar a análise de discursos em detrimento daquela das práticas, conferindo uma visão excessivamente plástica ao social. Desejando reintroduzir as instituições e as estruturas sociais diretamente na análise, propomos um vocabulário alternativo, em torno das identificações, imagens sociais e pertencimento. Desenvolvemos, então, o caso da construção de uma imagem social, aquela da Borgonha na III República, para dar a justa medida do conjunto das evoluções estruturais e institucionais indispensáveis ao êxito de uma mudança discursiva sobre os territórios.

Palavras-chave Construção de identidades, Imagem social, Mercado de vinhos, França, Entre guerras
Abstract

Through a history of the uses of the concept of identity in France, it is possible to identify an essentialist definition that is typical of both common sense and of some of the social science literature, and another, constructivist meaning that has imposed itself on the social sciences against the concept of culture, thereby establishing the current approach to the construction of identities. It seems as if the heuristic advantages of the latter formula have drained themselves, since they tend to privilege the analysis of discourse at the expense of practice, conferring an excessively plastic view of the social. Hoping to re-introduce institutions and social structure into the analysis, I propose an alternative vocabulary of identifications, social images and belonging. I then proceed to a case study of the construction of social image, that of Burgundy in the $3^{\text {rd }}$ Republic, so as to make evident the set of structural and institutional evolutions that are indispensable to the success of a discursive change concerning territories.

Key words Construction of identities, Social image, Wine market, France, Inter-war period 